\title{
Rationalizing Oral Corrective Feedback in Sudanese EFL Classrooms
}

\author{
Bashir Abuelnour Elbashir Hussein \\ Sur Vocational Training Center, Sur, Sultanate of Oman \\ Holi Ibrahim Holi Ali (corresponding author) \\ Rustaq College of Applied Sciences, Rustaq, Sultanate of Oman \\ School of Education \& Professional Development, University of Huddersfield, UK \\ E-mail: howlli2@yahoo.com
}

Received: 08-01-2013

doi:10.7575/aiac.ijalel.v.3n.3p.217
Accepted: 15-02-2014

Published: 01-05-2014

\begin{abstract}
This study is primarily investigating teachers' perceptions about the application of oral corrective feedback in Sudanese EFL classrooms. It attempts to explore and rationalize the application of oral feedback in an EFL context, specifically in Sudan. For this purpose, a questionnaire was designed and distributed to (70) EFL secondary school teachers. An observation checklist was also used during class visits to further support the qualitative data. The results showed that EFL teachers have different views about giving oral corrective feedback. The findings also revealed that recast is the most commonly used approach, followed by elicitation and metalinguistic feedback, respectively. Clarification requests were found to be the least commonly used approach. Regarding teaching language systems, it was found that recasts is the most common approach used in teaching vocabulary and pronunciation whereas metalinguistic is highly preferred in teaching grammar. The study concluded with some relevant recommendations: First, it is the responsibility of the concerned authorities to make the school environment a better place for learning; class size and learning aids are important to help facilitate the role of the teacher in offering good quality teaching where feedback is provided for every learner. Second, educators and experts should hold regular seminars and conferences, issue magazines and periodicals on feedback and other relevant ELT topics. Moreover, teachers should be trained on how to give feedback on oral production. Finally, teachers should push students towards pair/group work because by doing so this will provide opportunities for ST-ST and T-ST feedback.
\end{abstract}

Keywords: Rationalizing, oral corrective feedback, Sudanese EFL classrooms, clarification requests, metalinguistic, recast

\section{Introduction}

\subsection{Study Problem}

Gower (2005:163) explains that feedback is one of the most important responsibilities of a teacher. By providing ongoing feedback to your students would help you as a teacher to evaluate their success and progress. There are two types of classifications to feedback which are positive and negative, depending on the responses from the part of the learners. Positive feedback is when teachers reward learners for a good answer. This can help them to develop selfconfidence. Negative feedback, on the other hand, is used to help learners to understand what supposed to be changed in an utterance or a sentence in order to avoid an error. Negative feedback is usually used in teaching contexts which are characterized by the type of information which learners can use to revise and improve their language (Ellis: 1999). According to (Mosa, 2010) there is a lack of information concerning feedback in secondary schools, and teachers have no ability to research or read about this field of study. Therefore, this study is conducted to fill the gaps in oral corrective feedback. In secondary schools, in Sudan, students practise their speaking and writing skills as two significant aspects of their target foreign language study. As they are doing so, they mispronounce words, make syntactic errors or use words in an inappropriate context where they do not belong to. It may be important, then, for students to get feedback that makes them aware of the error and thus provides information about how to avoid making them in their future use of the language. In a language teaching situation, it can be helpful for teachers to be aware of the different types of errors that students are making when deciding whether to correct them or not and what type of feedback is suitable for them in this particular context. But how do teachers respond to students' errors? Do they react at all? And with what effect? Some researchers adhere to giving of feedback while others refute it altogether. Between advocators and refuters there are those who believe in the effectiveness of some types of oral feedback over the others. A considerable number of teachers have heard that recasts a type of feedback that involves reformulating the student's error into the correct form, is the most appropriate one, especially because it may decrease students' anxiety. Other teachers assumed that recasts are not effective and that pushing students to self-correct is a more appropriate technique (Mosa, 2010). Putting this confusing picture of error feedback in his mind, the researcher intends to investigate the 
types of oral feedback commonly used by secondary school teachers in Sudan and how these approaches are perceived by EFL teachers. The researchers intend to investigate recasts, clarification requests, elicitation and metalinguistic approaches as the most commonly used approaches of oral corrective feedback in classrooms. Detailed information about these approaches will be discussed later. This will help to fill the gap in literature as there is little, or almost nothing researched in this domain, in Sudan, and provides forwards recommendations which might be of a great help to EFL/ ESL in the world and in Sudan in particular. Concerning errors, Lightbown and Spada (1999) proposed four major types of oral corrective feedback that teachers use when approaching learners' errors. Therefore, this model is employed in this study because it is straight forward and relevant to the questions raised by the study. The model includes four types of oral corrective feedback which are: Clarification requests: is a type of oral corrective feedback where the teacher alerts the learner that a repetition or a reformulation is needed because his utterance has been misunderstood or that there is an error in it; recasts: is when the teacher repeats the learner's erroneous utterance, replicating the errors with an emphasis on the correct form, elicitation: is when the teacher asks questions in order to direct the learner to the correct form. Metalinguistic feedback: is when the teacher comments on the error, using language information about the error and correct the form of that error (Lightbown and Spada 1999). The researchers intend to investigate recasts, clarification requests, elicitation and metalinguistic approaches as the most commonly used approaches of oral corrective feedback in classrooms. This will help to fill the gap in literature as there is little, or almost nothing researched in this domain, in Sudan, and provides forwards recommendations which might be of a great help to EFL/ ESL in the world and in Sudan in particular.

\section{Research Questions}

This study attempts to answer the following questions:

1. How is the application of the approaches of oral corrective feedback perceived by EFL secondary school teachers?

2. What kind of oral corrective feedback is commonly used by EFL Sudanese secondary schools teacher?

3. What kind of oral corrective feedback is used by EFL Sudanese teachers in teaching language systems, e.g., (grammar, pronunciation \& vocabulary)?

4. Why is certain type of corrective oral feedback used more than others?

\subsection{Hypotheses}

1. The majority of EFL teachers in Sudanese secondary schools view oral corrective feedback approaches as important. However, they have mixed opinions about their use and applications.

2. Recast, clarification request and metalinguistic techniques are the most commonly used approaches of oral corrective feedback by EFL secondary schools teachers.

3. Clarification request, recast and metalinguistic techniques are the most widely used approaches of oral corrective feedback in teaching language systems such as grammar, pronunciation and vocabulary, respectively.

4. The main reason behind the use of certain oral corrective feedback over another is the type of textbook, teaching methodology used, the kind of training that teachers have had and students' level.

\subsection{Significance of the Study}

Since there is little knowledge, and in EFL context, the intent of my study is to explore EFL teachers' perceptions about feedback and to identify the kind of oral feedback given. In order to indicate the unique quality, you may include the following: filling a theoretical and practical gap in the literature, exploring an inconsistency in research findings, and clarifying conflicts between theories. This study derives its magnitude from the role of oral corrective feedback as a significant factor in helping students to develop their linguistic and language competences and capacities. This study intends to make an important contribution to the field. It will be of great importance to educators, practitioners and EFL teachers. The study deals with the most significant and fundamental issues in language pedagogy which is oral corrective feedback in EFL classroom. Teachers can evaluate their techniques in using oral feedback and then make new plans and strategies.

\section{Methodology}

The methodological approach underlined this study as a combination of qualitative and quantitative approach. Questionnaire and observation were employed to collect data to answer the questions raised by the study. The context of this study is Sudan, specifically at Omdurman locality. It focuses on EFL secondary schools teachers and their experiences with oral corrective feedback practices in EFL classroom. It attempts to investigate and explore the type of oral corrective feedback that is used in teaching English as a foreign language in Sudanese secondary schools find out teachers' perspectives towards oral corrective feedback, kind of feedback approaches in use and why certain approaches are used more frequently than others. Lightbown and Spada's model (1999) was employed. The model has been described as straightforward. It focuses on four types of feedback which have been investigated in the current study: Clarification requests: is where the teacher reminds the learner that a repetition or a reformulation is needed. It includes social formulas such as" Pardon me, Excuse me, I can't get your point". It may include a repetition of the error made by the student. Recasts: is when the teacher repeats the learner's utterance by replicating the error with little emphasis on the correct form. Moreover, elicitation techniques: is when the teacher asks questions in order to coach the learner to the correct form. Finally, metalinguistic feedback: is when the teacher comments on the error, using language information about the error and correct the form of that error. 


\subsection{Participants}

The total number of teachers participating in the study is 70 EFL secondary school teachers and all of them are Sudanese and they have been teaching in secondary schools for several years; they have an average of $6-7$ years of teaching experience. All of them are Arabic speakers (mother tongue) and they went for training to be EFL teachers in secondary schools. The teachers were chosen on the basis of their convenience and accessibility and they were selected randomly from the entire population. The students in these schools are all Sudanese. They are all monolingual students and they have the same cultural and educational background. Their ages range between 14 to 17 . The number of students in each class ranges between 30 to 40 students.

\subsection{Instruments}

The tools of inquiry which were used to collect data in this study were a combination of qualitative and quantitative tools. Both questionnaire and observation were used. Questionnaires could provide a relatively and straightforward approach to study people's attitudes. They can also be used to collect generalized information from almost any human population. Moreover, they can be extremely efficient at providing large amount of data, at relatively low cost, in a short period of time (Robson, 2011: 241). Therefore, questionnaires were used in this study. Additionally, observations were used to support and reinforce the qualitative data. One of the advantages of observation as a technique is its directness. You do not ask people about their views, feelings or attitudes; you watch what they do and listen to what they say and it seems to be the appropriate technique for getting "a real life" in the real world. (Robson, 2011: 316). Thus, observation was employed to observe live classes and find out what kind of oral corrective feedback is used in this particular context. A questionnaire was designed which is composed of four parts: Part one includes (9) statements which are meant to collect EFL secondary school teachers' perceptions about the use of oral corrective feedback approaches. It involves Likert scale which ranges from strongly agree to strongly disagree. Part two centers on approaches for giving oral corrective feedback and which are commonly used by EFL secondary school teachers in Sudan. It involves the four types of oral corrective feedback which are taken from Lightbown \& Spada's model (1999).The rationale behind using this model is that it is straight forward and relevant to the objectives of the study. Part three falls in three questions which are 11, 12 and 13 and the purpose of this part is to find out the kinds of oral corrective feedback used in teaching language systems (grammar, pronunciation and vocabulary). The respondents are asked to choose the kind of error feedback they usually use in teaching these language systems. Finally, part four is an open-ended question which intends to explore respondents' diverse views about why certain approach of oral corrective feedback is more effective than others. Al Samawi claims that observation is suitable for language teaching and classroom interaction. He also adds: In language teaching, observation has become one of the important methods for collecting data (Al Samawi, 2000: 42). Therefore observation was used as a technique to collect data. A digital recorder was used to record classroom interaction and the kind of feedback used in a real life context which was four secondary schools at Omdurman locality, in Sudan, two for boys and two for girls. Further, notes were taken to capture data which might not be attained by the recorder. The observation check list involves three parts which are type of feedback commonly used, type of feedback used in teaching language systems and how teachers react towards students' errors. Expert-validation is employed in this study. Both the questionnaire and the observation check list were validated by experts in Applied Linguistics and education, research methodology and psychology. All irrelevant items were taken out and clear questions were modified and some were deleted. Questionnaire's wordings and clarity were checked and verified against the study questions and objectives to meet the intended results. As a result, a new version was drafted and distributed. After piloting stage, the questionnaire was given to an expert in Applied Linguistics and Education to calculate its reliability coefficient. Spearman, Brown's equation was employed to calculate and compute the reliability coefficient of the questionnaire. It was found approximately 0.6110 which is somewhat high positive reliability.

\section{Theoretical Underpinnings}

\subsection{The Importance and Benefits of Oral Feedback in Classroom}

Language learners demand feedback on error in order to make progress in their ability to use a target language in more targets like ways (Krashen 1985).The importance of giving feedback to improve learning and achievement has been confirmed through research. Some researchers argue that constructive feedback is useful and helpful for learners to support them to write and speak well a foreign language. Yaakub, (2005: 14, as cited in Al Harrasi 2007) wrote that "an important component responsible for improving the writing would be the giving of feedback". Ellis (1999) explains that feedback which is provided by teachers to their students in their drafts, with an opportunity to revise and check this response, is one of the main keys to students development as writers. Furthermore, Ellis (2006) explains that teachers' feedback in grammar, vocabulary, spelling and punctuation helps students improve their writing. Reid (1993) and Hyland (1998) argue that feedback helps students to assess and modify their understanding and transfer what they have learnt from a task. Ellis (2006) emphasizes that feedback is important for three reasons. First, it is an opportunity for learners to expand their language in areas of vocabulary and grammar. Second, it helps them to get the information necessary for strengthening their background and learn new materials as well as suggesting their future reading and writing. Third, it helps them recognize and build upon their knowledge and experience. Moreover, Sadler (1998) emphasizes that feedback should enable learners to identify their learning gaps between current and desired performance and to take some future action that will close these learning gaps. Hattie\& Timperley (2007) believe that the most powerful feedback for learners is that which is regulatory because it involves learners to the greatest degree as participants in their own teaching and learning. Black et al. (1998) argue that dialogic feedback allows for discussion between student and teacher of a kind that promotes thinking and reflection and evokes and explores mutual 
understanding. Leki (1991) states that the role of the writing teacher is split into three incompatible persons: teacher as a reader, teacher as a coach and teacher as evaluator. Educators advocate teacher as a reader because it encourages learners to practice more of the writing skills. Moreover, teachers provide learners with useful comments which will enable them to improve their skills in the next task. Sugita (2006) argues that handwritten feedback falls into three types: statements, imperatives and questions. Results from his study show that imperative forms in giving feedback were found to be more influential and directive on revisions than questions and statements because the teacher's imperative comments seem to be direct comments which have a feeling of authority so that students pay a great deal of attention to teacher feedback, follow the instructions and revise the drafts regularly. White (2007: 299) wrote:

"Positive constructive feedback that celebrates students' successes helps keep them motivated and increases their confidence. It highlights for students the things that are important to focus on and directs their learning towards the next step".

Oral corrective feedback is a common means for teachers to share data with their students. Applying this approach, teachers verbally tell students how they are performing, with hot or instant feedback reported as more effective in reducing problems than delayed feedback (Rydahl, 2005). She explains: a teacher may tell a student who is working on improving his/her spelling "great job on your spelling test" "keep the good work up". Such feedback will, definitely influence future target performance. Further, (Hattie\& Timperely, 2007: 81) believe that feedback is one of the most powerful influencing factors on learning and achievement. Thus oral feedback appears to be a viable intervention strategy to improve learning outcomes for language students. Negotiation of form and negotiation of meaning are two important elements that oral feedback is highly concerned with. Schmidt \& Frota (1986) argue that negotiation of form in corrective feedback may create opportunities for foreign language learning because they may help foreign language learners to "notice the gap" between their own utterance and the target language and may help them to produce accurate output in the process of meaningful interaction (Lyster \& Ranta 1997). Sadler (1998) suggests that the goals of quality learning and related-achievement issues are best conveyed to students through a combination of verbal descriptions and exemplars. Verbal descriptions set the properties and the level of quality expected in relation to achievement of the learning goal while exemplars are concrete examples that typify the intended levels of quality. Sadler (1998) states that language students should understand the goals of learning that can be enhanced and achieved by feedback It is assumed that this understanding will lead students, who are more task oriented and better positioned, to make decisions about how to go about their learning (Hattie \&Timperely 2007). Additionally, Brown (2007) argues that verbal feedback is much more useful for students and it can convey more information than written feedback because you are able to use tone of voice, immediate feedback, face expressions and body language over and above the words you use. Verbal feedback allows learners to watch the body language of their teacher. Facial expressions and other physical clues can help both learners and teachers determine how words are being received. If you provide your comments in writing, you may not know how the reader is internalizing them and you may not intervene if a misunderstanding takes place. In face-to-face feedback there can be an instant exchange of ideas. Questions can be asked and answered while teacher is giving feedback. In face-to-face verbal feedback, there is interaction between student and teacher. The teacher can judge the effects his/her words are having and can add further explanation when students require it. The teacher can also estimate the effect of his/her feedback on students' faces and that if they seem to be over sensitive to critical comments, he/she has to soften his/her approach accordingly. In written feedback, tone is lost whereas in face-to-face feedback teachers can easily convey a sense of urgency, understanding, sympathy or something else. The tone of your voice, together with the words you speak, will convey precisely the message you want to deliver. Many researchers have concentrated on describing the characteristics of oral corrective feedback. Brooks (1960) and Hattie \& Timperley (2007) summarize the benefits of oral feedback as follows: First, feedback is a significant part of the formative assessment process. Formative assessment informs both teachers and students about how students are doing in relation to classroom learning goals. Giving good and effective feedback is one of the skills teachers need to master as part of good formative assessment. The power of formative feedback lies in its double barreled feedback, addressing both cognitive and motivational factors at the same time. Good feedback gives students information they need for their learning so they can understand where they are in their learning and what to do next (cognitive factor). Once they feel they understand what to do and why, most students develop a feeling that they have control over their own learning (motivational factor). Second, oral feedback is instant and immediate in receiving information. Third, oral feedback creates transparency and builds self-esteem of both the teacher and learner. Fourth, it is a good source of entertainment to eradicate boredom. Fifth, oral feedback has potential to enhance student performance, retention rates and competition rates. Sixth, in oral feedback, comments are more likely to be constructive and related to learning objectives. Seventh, students remember most of the content. Eighth, in oral feedback there is opportunity for student's voice. Finally, oral feedback can be more persuasive and you have the opportunity of getting closer to your students and win their trust. People, generally, trust what they can see with their eyes and hear with their own ears and, comparatively, written words are more inert, dead and may not be able to convey the full scope of your message (Brooks: 1960).

\subsection{Oral Feedback and L2 Acquisition}

According to nativists, the use of corrective feedback has little impact on language learning process since it merely affects performance and leaves the underlying competence (Schwarz 1993). That is the formation and restructuring of grammars is attributed to innate human linguistic mechanism (Schwarz 1993). Krashen (1985) explains that a nativist also repudiates any discernible effects of corrective feedback in SLA. Krashen affirms that any knowledge consciously learned through explicit instruction cannot have a significant impact on L2 acquisition. Swain's output hypothesis (1985), shedding light on the significance of output opportunities in L2 development, argues that this can help learners 
to make and test metalinguistic knowledge of how the L2 works. Schmidt ( 1986 ), in his noticing hypothesis, assumes that noticing is a prerequisite of learning, continuing that conscious attention must be paid to input in order for L2 learning to proceed. Moreover, according to Long (1983:451), corrective feedback provides direct and indirect information about the grammaticality of the utterances as well as additional positive evidence which may otherwise be absent in the output.

"negotiation of meaning, and especially negotiation work that triggers interactional adjustments by the native speaker, NS, or more competent interlocutor, facilitates acquisition because it connects input, internal learner capacities, particularly selective attention, and output in productive ways"

These interactional adjustments include: repetition, confirmation checks, reformulations or recasts, comprehension checks, clarification requests and completion or backtracking. Mackey (2000) provides two examples to show how negotiated interaction facilitates L2 development. The first example illustrates that the non-native speaker (NNS) does not understand the word "glasses ". The word is repeated several times by the native speaker (NS), and the original phrase is extended and rephrased, and finally a synonym is given:

NS: There's a.... a pair of reading glasses above the plant.

NNS: A what?

NS: Glasses reading glasses to see the newspaper.

NNS: Glassi?

NS: You wear them to see with, if you can't see, Reading glasses.

NNS: Ahh ahh glasses glasses to read...you say reading glasses.

NS: Yeah.

The second example shows that the NNS rephrases the original sentence in an effort to be understood. The NNS restructures output to facilitate that the NS understands his/her utterance.

NNS: And one more weep....weep... this picture.

NS: Huh?

NNS: Another one.. Like gun to shoot them.. weep.. weepon.

NS: Oh ok ok yeah I don't have a second weapon so that's another difference.

(Adapted from Mackey, 2000: 559)

Further, Long (1996: 413) points out that interaction also gives learners the opportunity to talk in L2, which, on one hand provides opportunity for student output and on the other hand provides useful feedback from teachers and peers, both of which hypothesized to be facilitative for second language acquisition (SLA). Long's (1996) believes that comprehensible input is not sufficient for language acquisition whereas Krashen (1985) believes that the part of interaction that does not contribute to a acquiring a language is the output produced by the language acquirer. Krashen (1985: 180) maintains that "comprehensible output is too scarce to make a real contribution to linguistic competence" and that comprehensible input will result in language acquisition whether "output" is present or not. However, Swain (1985) argues that language learners need the opportunity for meaningful and productive use of their existing linguistic resources and that this can be facilitated when they are pushed into making their output more grammatical. He suggests that learners' production will aid acquisition only if they are pushed. That could happen through conversations, which he calls "collaborative dialogues". In these conversations, learners produce a language which can be viewed as a sign of second language learning (Swain 1985: 320). Learners' errors play a significant role in second language acquisition (SLA). Corder (1967) claims that there are two schools of thought with regard to learners' errors. The first school believes that errors is a sign of our inadequacy of our teaching techniques and that errors would never be committed in the first place, if we were to achieve perfect teaching. The second school assumes that we live in an imperfect world and consequently errors will always occur in spite of our best efforts to avoid it. Therefore we should concentrate on techniques for dealing with errors after they have occurred. Moreover, Lyster and Ranta (1997: 38) point out that learner' errors are evidence of language learning; in the sense that learners are making creative attempts to use language beyond they have been taught. Corder (1967:166-167) distinguishes between two types of errors; errors of performance and errors of competence. Errors of competence are called "mistakes", and they are of no significance to the process of language learning because they are the products of (memory lapses, physical states such as tiredness and physical conditions such as strong emotions). As for the term 'error', it refers to the types of learners' errors which are systematic from which we are able to reconstruct his/her knowledge of the language to the date (for example, transitional competence).In addition, Hedge (2000) divides learners' mistakes into three categories: 'slips' are mistakes which are self-correctable once they occur; 'errors' are mistakes which students cannot correct themselves, and therefore need interference from teachers and 'attempts' are when students are trying to say something but they do not know the correct way of saying it. Harmer (2006: 99) has mentioned that it is the category of' errors ' that most concern teachers in L2 classrooms. Furthermore, Corder (1967: 166) points out that some researchers assume that the task of acquiring a second language is similar to that of acquiring a first language. In both cases the learner is using a definite system of language "built-in-syllabus" at every point in his/her development. And the learner's errors are evidence of this system and are themselves systematic. It is a way the learner has of testing his hypothesis about the nature of the language he is learning. Harmer (2006: 100) mentions that errors are part of students' inter-language, that is: "the version of the 
language which a learner has at any one stage of development, and which is continually reshaped as he/she aims towards full mastery of that language." In providing feedback to learners' errors, teachers should deal with them as helping process by reshaping process rather than telling students that they are wrong.

\subsection{Views on Oral Feedback.}

Although there are many advocates of oral feedback and also believers in the effectiveness of oral feedback, some educators and researchers still believe that oral feedback hinders learning. Krashen, 1985 and Truscott, 1996 argue that corrective feedback should not be given to learners because it can have potential negative effects on learners', and hence impeding the flow of normal communication. Ur (2008: 242) explains that feedback has two main major components: assessment and correction. In assessment, the learner is informed how well or badly he/she has performed a certain task. In correction, some specific information is provided on aspects of the learner's performance: e.g. through explanation or provision of better alternatives. According to Ur (2008: 243-244), different approaches provide different opinions on giving of feedback. The audiolingualism approach explains that negative assessment should be avoided since it functions as punishment and may inhibit or discourage learning process. Positive assessment provides reinforcement of correct responses and promotes active learning. The humanistic approach emphasizes that assessment should be positive or non-judgmental. The skill theory approach emphasizes that the learner needs constant and honest feedback for successful acquisition to take place. Regarding the correction of mistakes, the audiolingualism approach believes that learners' mistakes are, in principle, should not be avoided because they impede and limit progress. The latest is, in any case, not useful for learning; people learn by getting things right in the first place and having their performance reinforced. The cognitive code-learning approach emphasizes that mistakes are regrettable, but unavoidable part of learning: They should be corrected whenever they occur to prevent them occurring again. The inter-language approach opposes to the cognitive code-learning approach in that mistakes are not regrettable, but an integral and important part of language learning. Correcting them is a way of bringing the learner's "inter-language" close to the target language (Selinker, 1972).The communicative approach believes that not all mistakes need to be corrected: The main aim of language learning is to receive and convey meaningful messages, and correction should be focused on mistakes that impede meaning and cause misunderstanding, not on inaccuracies of usage. The monitor approach, according to Krashen (1985), believes that correction does not contribute to real acquisition of the language, but only to the learner's conscious "monitoring" of speech and writing. Hence the main activity of the teacher should be to provide comprehensible input from which the learner can acquire language, not to correct. Harmer (2006: 104-105) made a distinction between accuracy and fluency during oral feedback. Harmer believes that during communicative activities, teachers should not interrupt students in mid-flow to point out a grammatical, lexical or pronunciation error; since to do so interrupts the communication and drags the activity back to the study of language form or precise meaning. Teacher intervention in such circumstances can raise stress levels and stop learners acquiring the language. Harmer (2006: 105) argues that when teachers intervene, not only to correct but also to supply alternative modes of expressions to help students, they may deny students a learning opportunity. Harmer continues to say that teacher intervention may sometimes be necessary, but it is nevertheless unfortunate- even when we are using "gentle correction ". In Harmer's words:

"The best answer to the question when to intervene in learner's talk is: as late as possible. Nothing in language teaching is quite that simple, of course. There are times during communicative activities when teachers may want to offer correction or suggest alternatives because the students' communication is at risk, or because this might be just the right moment to draw the students' attention to a problem."

Harmer (2006:105) adds: "intensive correction can be just as unpleasant during accuracy work." Brown (2007), also, notices some disadvantages of verbal feedback. These can be summarized as follows: 1 . it is not easy for students to reflect accurately on verbal feedback because they tend to remember only part of it better than others; the reaction of students to verbal feedback can vary depending on their mood and state of mind at the time it is given. If they are feeling positive they might remember the positive and if they are feeling apprehensive, they might also recall the negative, some students can be embarrassed when they receive feedback (positive or negative) in a group situation. 2 . Feedback might be best delivered to groups and save specific points for individuals, and students may see teachers as figure of authority. This might create additional tension and cause them to receive feedback in a distorted way.

\subsection{Types of Oral Corrective Feedback}

In addition to recast, which is the most frequently used feedback; six other corrective techniques have been identified: explicit correction, clarification requests, metalinguistic information, elicitation, repetition and translation (Lyster \&Ranta 1997; Lightbown \& Spada, 1999 and Panova and Lyster 2002).

\subsubsection{Recast}

The term recast was originally used in the literature of L1 acquisition to refer to responses by adults to children's utterances (Nelson: 1984). Afterwards it merged into the domain of L2 acquisition in which different definitions were utilized. Additionally, Lyster \& Ranta (1997: 46) define recast as "teacher's reformulation of all or part of a student's utterance, minus the error. They note that recasts are generally implicit in that they may focus on one word only, what Oliver (1995) termed ' partial recast', whereas others incorporate the grammatical or lexical modification into a sustained piece of discourse, ' a full recast'. Recasts also include translations in response to a student's use of the L1. Translations are coded as recasts because they occur infrequently and, when they occur, translations clearly serve the same function as recasts, as Lyster and Ranta (1997: 47) suggest. Long (1996: 434) defines recast as "utterances which 
rephrase an utterance by changing one or more sentence components (subject, verb or object) while still referring to its central meaning." Mackey (2000: 341) specify that recasts: a reformation of the ill-formed utterance, expand the utterance in some way, retain the central meaning of the utterance, and follow the ill-formed utterance. Moreover, Chaudron (1977: 39) defines recast as "repetition with change" as a response to a learner error in which the teacher "simply adds correction and continues to other topics." Chaudron further distinguishes between "repetition with change " and "repetition with change and emphasis". He defines the latter as a response in which the teacher "adds (emphasis) to stress location of error and its correct formulation." Krashen (1985) claims that recast cannot lead to acquisition. Examples of recasts include the following dialogues:

Dialogue 1:

Student: camel is animal.

Teacher: of course a camel is an animal.

Dialogue 2:

Student: A generator produces electricity.

Teacher: Yes, A generator produces electricity.

\subsubsection{Clarification Requests}

Clarification request is a type of feedback that carries question indicating that the utterance has been ill-formed or misunderstood and that a reformulation or a repetition is required e.g. using phrases like excuse me!, What do you mean by...?. Or pardon! I cannot get your point'. This kind of feedback encapsulates "problems in comprehension, accuracy or both" (Lyster \& Ranta 1977: 47). Clarification requests, unlike other types of feedback, can be more consistently relied upon to generate modified output from learners since it might not supply the learners with any information concerning the type or location of the error. Examples of clarification requests include the following dialogue: Student: One day, an engineer visits an oil well in his car. Teacher: Pardon, again?

\subsubsection{Elicitation}

Elicitation is a correction technique that prompts the learner to self-correct (Panova \& Lyster 2002) and may be accomplished in one of three ways during face-to-face interaction. The first is the request for reformulations of an illformed utterance. The second is through the use of open questions. The third is through the use of pauses to allow a learner to complete an utterance. Therefore, elicitation falls in the middle of explicit and implicit continuum of corrective feedback. This kind of corrective feedback is not usually accompanied by other feedback types. The following dialogue is an example of this type of feedback:

Student: I like go to the zoo.

Teacher: Where else do you like going to?

Student: I like going to parks.

\subsubsection{Metalinguistic Feedback}

Moreover, Lyster \&Ranta (1997) categorize metalinguistic feedback as "comments, information, or questions related to the well-formedness of students' utterance, without explicitly providing the correct form." The least information category is metalinguistic comments which only indicate the occurrence of an error. Metalinguistic information indicates the occurrence of the error as well as offers metalanguage that alludes to the nature of the error. Metalinguistic question points to the nature of the error and attempts to elicit the information from the student (Lyster \& Ranta 1977:47). Examples of metalinguistic feedback include the following dialogues:

\section{Dialogue 1:}

Student: I visit my friend yesterday.

Teacher: present or past?

Student: I visited my friend yesterday.

Dialogue 2:

Student: I bought some apple.

Teacher: singular or plural?

Student: I bought some apples.

\subsubsection{Corrective Feedback and Learner's Uptake}

Lowen (2007 : 153) has mentioned that uptake is a term used to describe learners' responses to the provision of feedback after either an erroneous utterance or a query about a linguistic item within the context of meaning-focused language activities. Lyster and Ranta (1997: 52) defines uptake as: "refers to a student's utterance which immediately follows the teacher's feedback and which constitutes a reaction in some way to the teacher's intention to some aspect of the student's initial utterance." Two types of student's uptake are distinguished: 
1. Uptake that results in "repair" of the error on which the feedback focused. "Repair" refers to" the correct reformulation of an error as uttered in a single student turn and not to the sequence of turns resulting in the correct; nor does it refer to self-initiated repair." Lyster and Ranta (1997: 50) distinguish four types of repair.

1.1. Repetition: Refers to the student's repetition of the teacher's feedback when the later includes the correct form.

1.2. Incorporation: Refers to the student's repetition of the correct form provided by the teacher, which is then incorporated into a longer utterance produced by the student.

1.3. Self-repair: Refers to a self-correction, produced by the student who made the initial error, in response to the teacher's feedback when the latter does not already provide the correct form.

1.4. Peer-repair: Refers to a self-correction provided by a student, other than the one who made the initial error, in response to the teacher's feedback.

2. The second type of uptake is that which results in an utterance that still needs repair and it is referred to as " needs repair ". Needs repair include six types of utterances?

2.1. Acknowledgement: Refers to a simple 'yes' on the part of the student in response to the teacher's feedback, as if to say ( but you have just said it much better!). Acknowledgement also includes a 'yes' or 'no' on part of the student in response to the teacher's metalinguistic feedback.

2.2. Same error: Refers to uptake that includes a repetition of the student's initial error.

2.3. Different error: refers to a student's uptake that is in response to the teacher's feedback but that neither corrects nor repeats the initial error; instead, a different error is made.

2.4. Off target: refers to uptake that is clearly in response to the teacher's feedback turn but that circumvents the teacher's linguistic focus altogether, without including any further errors.

2.5. Hesitation: Refers to a student's hesitation in response to the teacher's feedback.

2.6. Partial repair: Refers to uptake that includes a correction of only part of the initial error.

\section{Results}

This part depicts the study results which were collected via questionnaires and observations.

\subsection{Questionnaire Results}

Table 1. EFL Secondary School Teachers' Perceptions about Oral Feedback \& its Use

\begin{tabular}{|c|c|c|c|c|c|c|c|c|c|c|c|}
\hline \multirow[t]{2}{*}{ No } & \multirow[t]{2}{*}{ Statements } & \multicolumn{2}{|c|}{ S. Agree } & \multicolumn{2}{|c|}{ Agree } & \multicolumn{2}{|c|}{ Not Sure } & \multicolumn{2}{|c|}{ Disagree } & \multicolumn{2}{|c|}{ S. Disagree } \\
\hline & & $\mathrm{F}$ & $\%$ & $\mathrm{~F}$ & $\%$ & $\mathrm{~F}$ & $\%$ & $\mathrm{~F}$ & $\%$ & $\mathrm{~F}$ & $\%$ \\
\hline 1 & $\begin{array}{l}\text { Students should be encouraged to speak in English, in class } \\
\text { and in public, regardless to correctness of their utterances. }\end{array}$ & 41 & 59 & 27 & 39 & 1 & 1 & 1 & 1 & 0 & $\mathbf{0}$ \\
\hline 2 & $\begin{array}{l}\text { Students should be helped to speak correctly, than get them } \\
\text { the courage to speak. }\end{array}$ & 11 & 16 & 23 & 33 & 4 & 6 & 29 & 41 & 3 & 4 \\
\hline 3 & $\begin{array}{l}\text { Using a mixed method by balancing both accuracy and } \\
\text { fluency is always better. }\end{array}$ & 33 & 47 & 33 & 47 & 2 & 3 & 2 & 3 & 0 & 0 \\
\hline 4 & $\begin{array}{l}\text { Correcting students' errors should be based on the learning } \\
\text { outcomes of the course or the lesson. }\end{array}$ & 27 & 39 & 30 & 43 & 8 & 11 & 5 & 7 & 0 & $\mathbf{0}$ \\
\hline 5 & $\begin{array}{l}\text { Giving oral feedback is of utmost importance in teaching } \\
\text { all skills. }\end{array}$ & 26 & 37 & 26 & 37 & 10 & 14 & 8 & 11 & 0 & $\mathbf{0}$ \\
\hline 6 & $\begin{array}{l}\text { All approaches for giving oral feedback, such as recasts, } \\
\text { clarification requests, elicitation and metalinguistic, should } \\
\text { be integrated in the classroom. }\end{array}$ & 36 & 51 & 21 & 30 & 6 & 9 & 4 & 6 & 3 & 4 \\
\hline 7 & $\begin{array}{l}\text { Oral corrective feedback is useful for teaching productive } \\
\text { skills only. }\end{array}$ & 9 & 13 & 15 & 21 & 13 & 19 & 29 & 41 & 4 & 6 \\
\hline 8 & $\begin{array}{l}\text { It is better to give direct oral feedback after lesson to } \\
\text { students making oral mistakes in the classroom in front of } \\
\text { the whole class. }\end{array}$ & 26 & 37 & 25 & 36 & 5 & 7 & 9 & 13 & 5 & 7 \\
\hline 9 & $\begin{array}{l}\text { It is better to give indirect oral feedback latter on to that } \\
\text { single student making oral mistakes in the classroom. }\end{array}$ & 8 & 11 & 20 & 29 & 8 & 11 & 26 & 37 & 8 & 11 \\
\hline
\end{tabular}

Table (1) illustrates EFL secondary schools teachers' perceptions about oral feedback and its use at Omdurman Locality in Sudan. In response to item (1), 59\% of the respondents strongly believed that students should be encouraged to speak in English, in class and in public, regardless to correctness of their utterances, while $39 \%$ of the respondents reported by "agree" and only $1 \%$ reported by "not sure" and another $1 \%$ by "disagree". It could be concluded that teachers should 
encourage students to use the language freely. This view is supported by Harmer (2006). During communicative activities, teachers should not interrupt students in mid-flow to point out a grammatical, lexical or pronunciation error; since to do so interrupts the communication and drags the activity back to the study of language form and precise meaning." As for item (2), 16\% of the respondents said that they "strongly agree" that students should be helped to speak correctly, while 33\% responded with "agree" and 6\% "not sure ". On the other hand, $41 \%$ of the respondents "disagreed" with the statement and only $1 \%$ "strongly disagreed". It is quite obvious that respondents view error correction during oral communication differently. Some believed that teachers should help students to produce correct utterances whereas the majority believed that teachers should not. Again this view is supported by Harmer (2006):

"When teachers intervene, not only to correct but also to supply alternative modes of expressions to help students, they may deny students a learning opportunity. Yet there are times during communicative activities when teachers may want to offer correction or suggest alternatives because the students' communication is at risk, or because this might be just the right time to draw the students' attention to a problem."

Concerning item (3), 47\% of the respondents "strongly agreed" and another $47 \%$ "agreed" that it is better to use a mixed method by balancing both accuracy and fluency, whereas 3\% of the respondents were "not sure" and 3\% "disagreed" . Harmer (2006) supported this view when he made an important distinction between accuracy and fluency during oral feedback. He explained that there are times when teachers need to intervene when students' communication is at risk and there are times when teachers do not interrupt students in mid-flow because this might distort communication. Regarding item (4), 39\% of the respondents "strongly agreed" that correcting students' errors should be based on the learning outcomes of the course or the lesson, $43 \%$ responded by "agree" and $11 \%$ responded by "not sure". On the other hand only $7 \%$ "disagreed" with the statement. It is quite evident that most of the respondents viewed error correction as a stage associated with the learning outcomes of the lesson or the course. This view is supported by (Ellis: 1999). He explained:

"Teachers often tend to correct errors during one part of a lesson, but not in the other parts, or stop giving feedback if uptake does not seem to occur."

In response to item (5), whether giving oral feedback is of utmost importance, $37 \%$ of the respondents "strongly agreed", 37\% "agreed" and 14\% were "not sure". On the other hand, only 11\% "disagreed". Many researchers advocated the views on the importance of giving oral feedback (Sadler 1998; Hattie \& Timperley 2007; Lyster \& Ranta 1997). On the contrary, there were those who argued that corrective feedback should be abandoned because it can have potential negative effects on learners' affect (Krashen 1985, Truscott 1996). As for item (6), 51\% of the respondents "strongly agreed" that all approaches for giving oral feedback should be integrated in the classroom, 30\% "agreed" and $9 \%$ were "not sure". On the other hand only $6 \%$ "disagreed" and $4 \%$ "strongly disagreed". It is clear that the majority of the respondents preferred integration of all approaches. This view is supported by (Van Lier: 1988): "The situation and the atmosphere in the classroom have an influence both on the type of correction used by the teacher and the response by the student".

Ellis (1999) also indicated that one single teacher often uses a mix of different types of feedback, or uses the same type of feedback regardless of the type of error made by the students. Concerning item (7), whether oral corrective feedback is useful for teaching productive skills, only 13\% responded by "strongly agree", $20 \%$ by "agree" and $19 \%$ by "not sure". On the other hand, $41 \%$ of the respondents responded by "disagree" and $6 \%$ by "strongly disagree". Regarding item (8), $37 \%$ of the respondents "strongly agreed" that it is better to give direct oral feedback to students making oral mistakes in the classroom and in front of the whole class, 36\% "agreed", 7\% were "not sure ", 13\% "disagreed" and 7\% "strongly disagreed" with the statement. It is obvious that the majority of the respondents preferred to give direct feedback in the classroom and in front of the whole class. This view is supported by Brown (2007): Finally, item (9) shows EFL teachers perceptions about giving oral feedback to students making oral mistakes latter on in the classroom. $11 \%$ responded by "strongly agree", $29 \%$ "agreed" and 11\% were "not sure ". On the other hand, 37\% of the respondents reported by "disagree" and $11 \%$ by "strongly disagree".

Table 2. Types of oral Feedback Commonly Used by EFL Secondary Schools Teachers

\begin{tabular}{llcc}
\hline No & Type of Feedback & Frequency & Percentage $\%$ \\
\hline 1 & Clarification requests & 33 & $47 \%$ \\
2 & Recasts & 49 & $70 \%$ \\
3 & Elicitation & 39 & $56 \%$ \\
4 & Metalinguistic & 37 & $53 \%$ \\
\hline
\end{tabular}

Table (2) depicts the types of oral corrective feedback commonly used by EFL secondary schools teachers. Results from the table can be interpreted as follows: $47 \%$ of the respondents reported that they use "clarification requests", $70 \%$ said they use "recasts", 56\% use "elicitation" and 53\% use "metalinguistic". It is quite evident that the majority of EFL secondary school teachers at Omdurman Locality, in Sudan, use recasts in correcting students' errors. Previous studies by (Caroll \& Swain 1993; Lyster \& Ranta 1997; Panova \& Lyster 2002) revealed that recast is the most frequent used corrective feedback. 
Table 3. Types of oral Feedback Commonly Used by EFL Secondary Schools Teachers in Teaching Grammar Skills

\begin{tabular}{llcc}
\hline No & Type of Feedback & Frequency & Percentage $\%$ \\
\hline 1 & Clarification requests & 7 & $10 \%$ \\
2 & Recasts & 16 & $23 \%$ \\
3 & Elicitation & 9 & $13 \%$ \\
4 & Metalinguistic & 49 & $70 \%$ \\
\hline
\end{tabular}

Table (3) displays the types of oral feedback commonly used by EFL secondary schools teachers in teaching grammar skills. Results from the table can be interpreted as follows: $10 \%$ of the respondents said they use "clarification requests" in teaching grammar, 23\% indicated that they use "recasts", $13 \%$ use elicitation and $70 \%$ use metalinguistic. It is quite evident that "metalinguistic" is highly preferred by EFL teachers in teaching grammar at Omdurman Locality in Sudan. This view is supported by Swain (1985); he argued that learners need the opportunity for meaningful use of their existing linguistic resources and that this can be facilitated when they are pushed into making their output more grammatical.

Table 4. Types of oral Feedback Commonly Used by EFL Secondary Schools Teachers in Teaching Pronunciation

\begin{tabular}{llcc}
\hline No & Type of Feedback & Frequency & Percentage $\%$ \\
\hline 1 & Clarification requests & 19 & $27 \%$ \\
2 & Recasts & 34 & $49 \%$ \\
3 & Elicitation & 13 & $19 \%$ \\
4 & Metalinguistic & 10 & $14 \%$ \\
\hline
\end{tabular}

Table (4), illustrates EFL views about the types of oral feedback commonly used in teaching pronunciation. Results can be interpreted as follows: $27 \%$ of the respondents reported that they use "clarification requests" in teaching pronunciation, $49 \%$ said they use recasts, $19 \%$ use "elicitation" and $14 \%$ use "metalinguistic". It is quite evident that recast is preferred by the majority of EFL teachers in teaching pronunciation. This view is supported by (Lyster \& Ranta 1997; Panova \& Lyster 2002; and Caroll \& Swain 1993).

Table 5. Types of oral Feedback Commonly Used by EFL Secondary Schools Teachers in Teaching Vocabulary

\begin{tabular}{llcc}
\hline No & Type of Feedback & Frequency & Percentage $\%$ \\
\hline 1 & Clarification requests & 12 & $17 \%$ \\
2 & Recast & 32 & $58 \%$ \\
3 & Elicitation & 28 & $40 \%$ \\
4 & Metalinguistic & 8 & $11 \%$ \\
\hline
\end{tabular}

Table (5) shows types of oral feedback commonly used by EFL secondary school teachers in teaching vocabulary. Results indicate the following: $17 \%$ of the respondents said they use "clarification requests", $58 \%$ use "recasts", $40 \%$ use "elicitation" and only $11 \%$ use "metalinguistic". It is quite evident that recasts is the most commonly used approach in teaching vocabulary at Omdurman locality in Sudan and this view is supported by many researchers such as (Lyster \& Ranta 1997; Panova \& Lyster 2002 and Caroll \& Swain 1993).Regarding part four of the questionnaire, which is question no (14), whether certain approaches of oral corrective feedback are more effective than others, participants' answers yielded the following results:(32) of the participants didn't complete that part of the questionnaire. (8) Of the participants thought that elicitation is more effective than other approaches. They thought that elicitation approach provides a chance for students to correct themselves under the control and supervision of the teacher. One of the participants explained:" I think elicitation approach is more effective because it helps the teacher to correct students' errors in a simple way and helps students learn how to correct themselves."

Another participant explained: "I think elicitation approach is more effective because it gives students a chance to analyze the context which is given by the teacher. Here the students are encouraged to solve the problem by themselves rather than to be corrected explicitly." Moreover other participants thought that elicitation approach encourages learners to participate and it gives them high confidence. They also thought that having students correcting their errors under the control of the teacher would improve their level of learning.

The metalinguistic approach is preferred by three participants. They thought that this approach helps learners to correct themselves, enriches oral production and keeps speaking going on. One of the participants explained:" Metalinguistic is 
more effective than other approaches because the teacher makes the student corrects his/her own errors without being embarrassed in front of the whole class".

The clarification request approach is preferred by three participants. They thought that this approach helps learners to engage in useful interaction with their teacher and helps them to participate effectively. One of the participants explained: "I think clarification request is better than other approaches because it helps learners to express themselves freely. Sometimes they have good ideas but they don't know how to express them correctly".

(5) of the participants thought that (recast) is more effective than other approaches. They justified their preference as follows:

1 / Students get the correct answer immediately.

2 / Recast doesn't confuse learners.

3 / Students can learn from repetition.

4/ Recast saves time, for both the teacher and the student.

Only two participants preferred recast and metalinguistic over the other approaches because they thought that they develop accuracy as students understand easily by repetition and in the metalinguistic approach correction is done through explanation of rules. Only one participant thought that metalinguistic and elicitation are more effective than other approaches because in metalinguistic you just give students a hint and you make them use their minds to reconsider their utterance and in elicitation you make the student correct his/her own error without being embarrassed in front of the whole class. The majority of the participants thought that all approaches should be applied, depending on the situation. One of the participants explained "The students' levels are different. So, it is better to use the approach that best suits each student". Another participant adds "Certain approaches are more effective than others because there are individual differences among learners. So we should use the approach that best suits their level (12) of the participants just said that certain approaches are more effective but they didn't say which ones and why.

\subsection{Observation Results}

This section introduces results emerged from classroom observations. The results show:

1. The first lesson the researcher observed was in A school for Boys. The teacher was teaching grammar, comparative and superlative adjectives. It was an input for a reading passage "A visit to the zoo". The teacher is an M.A holder and had his CELTA professional training. After explaining the rule to the class, he gave them time to complete an exercise which was on the board. Pair checking was done and then he discussed the answers with the class. As the teacher was doing so, the researcher was able to notice some of the methods the teacher used to correct students. The following examples showed some errors made by students and how the teacher reacted towards them:

Example (1)

T: What's the comparative of good?

St: Best

T: Comparative! (Saying it with a rising intonation to indicate that the student's answer is incorrect.).

St: Better

T: O.K

It's obvious that in this example the teacher used (clarification request) approach to correct the student as he indicated to the student that his answer was incorrect. The type of "Uptake" was self-repair as the student corrected himself in .response to the teacher's feedback

Example (2):

$\mathrm{T}$ : The word "fierce", how many syllables are there?

ST1: Two

T: Two... (pauses for a while which was understood by other students that the answer is wrong.(

ST2: One syllable.

T: Correct

In this example the teacher used elicitation approach to correct the student as he indicated this by his silence. The type .of "Uptake" was "Peer-repair" as correction was made by a student other than the one who made the initial error

Example (3):

$\mathrm{T}$ : What's the meaning of "platform"?

ST: Tareeq (giving the meaning of the word in his L1 which is equivalent to" Road" in English).

T: Giving more explanation (I am now standing on a platform).

ST: In his L1 (Mastaba ya Ustaz)

$\mathrm{T}:(\mathrm{Sah})$ 
In this example, the teacher used metalinguistic approach to help the student guess the correct meaning of the word as he explained the meaning in an example sentence. The type of "Uptake" was self-repair as the student corrected himself in response to the teacher's feedback.

Example (4):

T: How are lions dangerous?

ST: They are fierce animal.

$\mathrm{T}$ : Countable or uncountable?

.ST: They are fierce animals

T: Good

Again, the teacher used metalinguistic to correct the student's erroneous utterance as he explained this by giving the rule. The type of "Uptake" was self-repair as the student corrected himself in response to the teacher's feedback.

2. The second lesson the researcher observed was in B Secondary School for Boys (private). The lesson was an open discussion. The teacher asked students' opinions about the deterioration of English language in Sudan. The students gave their opinions in an interesting and expressive way. Actually, the class was an advanced learners' class and most of the feedback used was positive. The teacher used words and phrases like "good", "well done", "thank you "and" "you're right" to comment on students' utterances. However, the researcher was able to catch one error made by one of the students when he said: "In America and Britain, people doesn't care about grammar". But this error passed unnoticed by the teacher; or most probably he noticed that but he didn't want to interrupt the flow of the language.

3. The third school that the researcher visited was $\mathrm{C}$ secondary school for girls. The teacher was teaching grammar, personal pronouns. The researcher was able to notice two error corrections as shown in the following examples:

Example (1):

T: Who can change the object to a pronoun in the sentence: "I met Ahmed".

ST: I met he.

T: No, It's wrong.

ST2: I met him.

T: That's right.

In this example the teacher used direct negative feedback which doesn't fit in any of the four oral corrective feedback approaches. However, it was close to clarification request, but a harmful one. The type of "Uptake" was Peer-repair "as correction was provided by a student other than the one who made the initial error.

Example (2): Changing an object to a pronoun.

T: I visited Ahmed and Omar.

ST: I visited they.

$\mathrm{T}$ : I visited them.

ST: I visited them.

In this example the teacher used (recast) to correct the student as he repeated the student's utterance to correct the erroneous word. The type of "Uptake" in the student's response was repair-repetition type as student repeated the teacher's feedback.

4. The fourth lesson the researcher observed was in D Secondary School for Girls. It was a reading passage "Types of Animals". Two examples of error corrections were noticed:

Example (1):

$\mathrm{T}$ : What are the two types of animals mentioned in the text?

ST1: Wild animals and farm animals.

T: Wild animals and..... (pauses to indicate that the second part of the answer is wrong.

.ST2: Wild animals and domestic animals

\section{.T: Correct}

In this example the teacher used elicitation approach to correct the student's error as he signaled to another student who provided the correct answer. The type of "Uptake" was Peer-repair as correction was provided by a student other than the one who made the initial error

Example (2): (Changing from singular into plural)

T: Who can spell the word "donkeys"?

ST: d--o--n--k--e--i--e--s

.T: The word ends in a vowel 
ST: d--o--n--k--e--y--s

\section{.T: That's right}

In this example the teacher used metalinguistic approach to correct the student as he explained that by giving the rule. The type of "Uptake" was self-repair as correction was provided by the student who made the initial error, in response to the teacher's feedback

\subsection{Results in Terms of Hypotheses}

The purpose of this section is to present the statistical results in term of frequencies and percentages as they pertain to the hypotheses. In chapter (1), four hypotheses were addressed. Each hypothesis was stated and followed by a discussion of the statistical results which related to it. In this chapter these hypotheses are listed below with a description of the outcome of each in form of a summary. Regarding hypothesis 1, the majority of EFL teachers in Sudanese secondary schools view oral corrective feedback approaches as important. However, they have mixed opinions about their use and applications. The results which have been presented thus far show that the majority of EFL teachers in Sudanese secondary schools have mixed opinions about the use of oral corrective feedback and view them as important (table 1,p.37-38 ). Thus, the findings of this study provide strong support for hypothesis 1 . As for hypothesis 2, recast, clarification request and metalinguistic techniques are the most commonly used approaches of oral corrective feedback by EFL secondary schools teachers. Results presented in (table,2,p.40) indicated that recast, elicitation and clarification requests are the most commonly used approaches, respectively, rather than recast, clarification request and metalinguistic as stated in the hypothesis. Therefore, the findings, partly, confirm hypothesis 2. Concerning hypothesis 3, clarification request, recast and metalinguistic techniques are the most commonly used approaches of oral corrective feedback in teaching language systems such as grammar, pronunciation and vocabulary respectively. From data displayed in (tables 3, 4, 5, pp.41-42), it can be seen from teacher's responses that recast is commonly used by EFL secondary school teachers for teaching vocabulary and pronunciation and metalinguistic for teaching grammar. Therefore, hypothesis 3 is not strongly supported by the findings of this study. For hypothesis 4 , the main reason behind the use of certain oral corrective feedback over another is the type of textbook, teaching methodology used, the kind of training that teachers have had, students' level, etc. Results collected from qualitative data in the open-ended question (no 14) in the questionnaire showed that findings revealed that the main reasons behind using one feedback approach over another are 'simplicity', 'immediateness', " promotion of critical thinking", "differences in teaching context" rather than teaching methodology used, the kind of training that teachers have had, students' level, etc. as stated in hypothesis 4 . Thus, the findings of the study do not provide strong support to hypothesis 4.

\section{Conclusions and Recommendations}

\subsection{Conclusions}

The findings and conclusions of this study can be summarized as follows:

1. Teachers perceived oral corrective feedback differently.

2. All approaches of oral feedback were used in classrooms, unconsciously, with tendency to recasts approach.

3. Metalinguistic approach was found to be preferable in teaching grammar, recast for vocabulary and pronunciations and elicitations and clarification requests were the least used in teaching English at secondary schools in Sudan.

4. Preference of one approach over another was found due to factors such as level of students, simplicity, and promotion of critical thinking, self-confidence, immediateness and difference in contexts. The text books and teachers' training were not indicated as reasons behind using one approach over another. It could be concluded that the findings of this current study supported the previous research findings but in other contexts. Also the findings reported in the current study indicated one important issue which is the use of all feedback approaches, though teachers need to be enlightened on its effectiveness.

\subsection{Recommendations}

Taking into account the results of the study, the present status of oral corrective feedback in Sudan, the following points are offered as recommendations:

1. The concerned authorities should make the school environment an attractive place for both the student and the teacher; classrooms should have reasonable number of students and should be equipped with the minimum learning aids to help facilitate the role of the teacher in achieving good quality teaching, by giving useful feedback to every learner.

2. Educators and experts should try to stress on the importance of oral corrective feedback by holding regular seminars and conferences and by issuing specialized magazines and periodicals on the topic.

3. Teachers should receive training on how to give feedback during oral production.

4. Students should be encouraged to work in pairs and groups where there is an opportunity for ST-ST and T-ST feedback to take place. 


\section{References}

Al-Harassi, S. (2007). An Analysis of the Nature of Oral corrective Feedback Types (in particular recasts) used by Omani Teachers in Cycle One and Cycle Two English basic Education Classroom, and their Effects on Learners' Immediate Response. Unpublished MA thesis, University of Stirling, UK.

Al-Samawi, A. M. (2000). Introduction to: Research Methods Techniques in linguistics and literature, Sana'a Black,P, et al ( 1998 ). Inside the Black Box. Phi Delta Kappan, 80(2), 139-148.

Brooks, N. (1960). Language and Language Learning: Theory and Practice. New York: Harcourt, Brace and World. Brown, H.D. (2007). Principles of Language Learning and Teaching. New York. Pearson Education.

Carroll, S., \& Swain, M. (1993), Explicit and Implicit Negative Feedback. Studies in Second Language Acquisition, 15, 357-386.

Chaudron, C. (1986). Teachers' Priorities in Correcting Learners' Errors in French Immersion Classes. In Day, R. (ed.), Talking to Learn: Conversation in Second Language Acquisition ( p. 64-84 ). Rowley, Massachusetts: Newbury House Publishers.

Chaudron, C. (1977). Second Language Classrooms. Research on Teaching and Learning. Cambridge, UK: Chun, A. (1982). Errors, Interaction, and Correction. A study of native/non-native conversation. TESOL Quarterly, 16, 537-547

Corder, S. (1967). The Significance of Learners' Errors. IRAL, 5(4), 1967.

Ellis, R. (1999). Second language Acquisition. New York: Oxford University Press.

Ellis, R. (2006). Explicit and Implicit Corrective Feedback and the Acquisition of L2 Grammar. Studies in Second Language Acquisition. Newbury House Publishers.

Gower. (2005). Teaching Practice: A Handbook for Teachers in Training. England: Macmillan education.

Harmer, J. (2006). The Practice of English Language Teaching. England: Longman.

Hattie, J., \& Timperley, H. (2007). The Power of Feedback. Review of Educational Research, 77 (1), 81-112

Hedge, T. (2000). Teaching and Learning in the Language Classroom. Oxford: Oxford University Press.

Hyland, F. (1998). The Impact of Teacher Written Feedback on Individual Writers. Journal of Second Language Writing, 7 (3), 255-286.

Krashen, S. (1985). The Natural Approach- Language Acquisition in the Classroom. Oxford: Pergamon.

Larsen, E. (1998). Feedback: Multiple Purposes for Management in Classrooms. Journal of Management Education, 22(1), pp.49-62.

Leki, I. (1991). The Preferences of ESL Students for Error Correction in College-level Writing Classes. Foreign Language Annals, 24, 203-218.Press.

Lowen, S. (2007). Measuring the Effects of Oral Corrective Feedback on L2 Knowledge. Oxford: Oxford University Press.

Lightbown, P.M \& Spada, N. (2006). How Languages are Learned. Oxford: Oxford University Press.

Long, M. H. (1983). Native-speaker/ Non-native Speaker Conversation and the Negotiation Comprehensible Input. Applied linguistics, 4, 126-141

Long, M.H. (1996). The Role of the Linguistic Environment in Second Language Acquisition. Handbook of Second Language Acquisition. CA: Academic Press.

Lyster, R. \& Ranta, L. (1997). Corrective Feedback and Learner Uptake: Negotiation of Form in Communicative Classrooms. Studies in Second Language Acquisition, 19(1), 37-66

Lyster, R. (1998a). Form in Immersion Classroom Discourse: In or Out of Focus? Canadian Journal of

Mackey, A. (2000). How do learners perceive interactional feedback? Studies in Second Language Acquisition, 22, 471497

Mosa, M. A. (2010). Feedback as a Tool to promote Students' Speaking Skills. MA dissertation, Nile Valley University, Sudan.

Nelson,K. (1984). The Development of Oral and Written Language in Social Contexts pp.31-56. Norwood, NJ: Ablex.

Oliver, R. (1995). Negative Feedback in Child NS-NNS Conversation. Studies in Second Language Acquisition, 17, 459-481

Panova, I. \& Lyster, R. (2002). Patterns of Corrective Feedback and Uptake in an Adult ESL Classroom. TESOL Quarterly, 36, (4), 573-595.

Reid, J.M. (1993). Teaching ESL Writing. NJ: Prentice Hall Regents.

Robson, C. (2011). Real World Research (3rd edition).Wiley: UK

Rydahl, S. (2005). Oral Feedback in the English Classroom Teachers' Thought and Awareness. Karltad University. 
Sadler, R. (1998). Formative Assessment: Revisiting the Territory. Assessment in Education: Principles, Policy and Practice, 5(1), 77-84.

Schmidt, R., \& Frota, S. (1986). Developing Basic Conversational Ability in a Second Language: A case Study of an Adult Learner of Portuguese./Talking to learn: Conversation in Second Language Acquisition. Rowley: Newberry.

Schwartz, R. (1993). On Explicit and Negative Data Effecting and Affecting Competence and Linguistic Behavior. Studies in Second Language Acquisition, in Day, R (ed) pp 147 -163

Selinker, L. (1972). Interlanguage. IRAL. 10.2: 213-223

Sugita, Y. (2006). The Impact of Teachers' comment Types on Students' Revision. ELT Journal, 60(1), pp. 34-41.

Swain, M. (1985). Communicative Competence: Some Roles of Comprehensible Input and Comprehensible Output in its Development: Newberry House

Truscott, J. (1996). The Case against Grammar Correction in L2 Writing Classes. Language learning, 46, $327-369$.

Ur, P. (2008). A course in Language Teaching: Practice and Theory. Cambridge: Cambridge University Press.

Van Lier, L. (1988). The Classroom and the Language Learner. London: Longman.

White, S. (2007). Investing Effective Feedback Practices For Pre-service Teacher Education Students on Practicum. Teaching Education Journal, 18(4), pp. 299-311. 